\title{
$\pi D-14.000$
}

\author{
UNCIASSIFIED
}

ANALYTICAL CHEMISTRY OF THE POLYPHOSPHATES

by

Wm. Rieman III and Herbert I. Rothbart

CONTRACT: $\operatorname{AT}(30-1)-1306$

October 17, 1961

\author{
Rutgers, The State University \\ New Brunswick, N. J.
}

\section{UNCIASSIFIED}

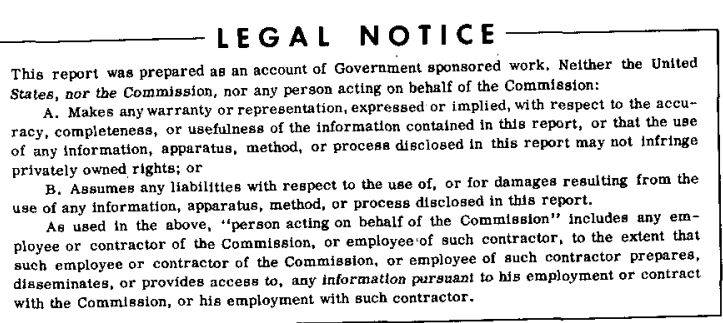


TABLE OF CONTENTS

Page

I. Introduction ................. I

A. Purpose and Scope of the Project ....... I

B. Background Information .......... 1

C. Summary of Results . . . . . .... 3

II. Experimental Work. ............ 4

A. Precipitation of Linear Phosphates . . . . . 4

B. Anion-exchange Chromatography ....... 4

C. Isolation of the Unknown Compound . . . . . 6

D. Titration of End Groups .......... 8

E. Paper Chromatography .......... 8

III. Results and Conclusions ........... 9

A. Precipitation of Linear Phosphates . . . . . 9

B. Anion-exchange Chromatography ........ 11

C. Isolation of the Unknown Compound ....... 12

D. End-group Titrations .......... 13

E. Paper Chromatography .......... 16

IV. Future Plans ............. 17

A. Analysis of Linear and Cyclic Phosphates in the Presence of One Another........ 17

B. Improvement of the Chromatographic Technique : 18

C. Identification of the Unknown Cyclic ..... 18

D. Identification of All Peaks . . . . . . I I8

E. Search for Higher Cyclics ......... 18

V. Acknowledgment ................ 19

VI. References ............... 20

VII. Reports and Papers Resulting from Work of This

Contract ................. 21

Nifl. Financial Statements.$\cdots \cdot \cdots \cdot \overbrace{22}$ 


\section{INTRODUCTION}

\section{I.A. PURPOSE AND SCOPE OF THE PROJECT}

The objective of this investigation is to develop adequate methods for the determination of the molecular composition of mixtures of condensed phosphates. This problem is logically divided into two parts.

The first part involves the isolation and subsequent determination of individual species of condensed phosphates, both linear and cyclic. In the series of linear polymers, $\mathrm{Na}_{n_{+}} \mathrm{P}_{n_{3}} \mathrm{O}_{3+1}$, the difference in properties between adjacent members becomes less and less as $n$ increases. Therefore the isolation of each successive member of the series becomes more and more difficult; and there must be a limit (probably $n \cong 14$ ) beyond which the isolation of individual molecular species is utterly impracticable.

In the region beyond this limit, it is still possible to separate the polymer mixture into several fractions each of which will contain a comparatively small range of molecular weights. From the guantity and average molecular weight of each fraction, the molecular-weight distribution can be calculated. This was the objective of the second part of this project.

\section{I.B. BACKGROUND INFORMATION}

The isolation of individual condensed phosphates was attacked in this project by anion-exchange chromatography. In 1956, a method $^{20}$ was described for the separation and determination of orthophosphate, pyrophosphate, triphosphate, tetraphosphate, trimetaphosphate, tetrametaphosphate and Graham salt in mixtures 
containing each of these constituents. This method and modifications $8,4,0,7$ of it are widely used in the routine analysis of phosphate mixtures. Separation by ion-exchange chromatography of the linear phosphates up to the dodecamer has been reported by Matsuhashi and up to the tetradecamer by Jameson. ${ }^{3}$ These investigators did not separate the cyclic polymers from the linear by ion-exchange chromatography.

Until 1956, it was generally believed that only two cyclic polymers of orthophosphate exist, the trimeta- and tetrametaphosphates. However, in a study of partly degraded Graham salt by two-dimensional paper chromatography, Van Wazer and Karl-Kroupa found a distinct spot that was probably due to pentametaphosphate and a continum extending from the origin almost to this spot, which they interpreted as due to higher cyclic polymers, up to octa- or nonametaphosphates. Prior to the work at Rutgers described in this report, no evidence had been obtained by ion-exchange chromatography for the existence of these higher cyclic polymers.

Nobody has succeeded in isolating by a single ion-exchange elution the individual phosphates from a mixture containing the first four linear compounds plus tri- and tetrametaphosphates. (Peters ${ }^{20}$ method reguires two elutions.) Furthermore, it seems very unlikely that this will be achieved in the foreseeable future. When the analyst has to deal with mixtures containing higher linear and cyclic polymers in addition to those mentioned above, 
the best approach to the problem is probably to devise a chromatographic method that will separate each linear compound from the other linear compounds and to apply to each fraction of eluate some subsidiary method to separate the linear compound from the cyclic compound (if any) occurring in the same fraction or to devise a method for the determination of each in the presence of the other. Some promising results on the selective precipitation of linear compounds with barium chloride were discussed in the last report.

In the last report of this project, ${ }^{22}$ it was stated that a satisfactory method had been developed for determining the molecular-weight distribution of Graham salt. A paper describing this method has been accepted for publication in The Joumal of Polymer Science.

\section{I.C. SUMMARY OF RESULTS}

1. Additional data have been obtained on the separation of linear polymers from cyclic polymers by precipitation with barium chloride.

2. An unexpected peak has been observed in the anion-exchange chromatography of a sodium polyphosphate of $\bar{n}$ (average degree of polymerization) $\cong 6$.

3. The compound represented by this peak has been isolated. This involved separation of it from the much larger quantities of potassium chloride and acetate buffer contained in the eluate. 
4. An end-group titration of this compound by microtechnique has proved unequivocally that it is a cyclic phosphate.

5. Work is in progress to identify this compound, i.e., to find how many phosphorus atoms there are per molecule. Although this work is not completed, the evidence from its position in the elution graph by ion-exchange chromatography and from paper chromatography indicate that it is probably pentametaphosphate, $\mathrm{Na}_{5} \mathrm{P}_{8} \mathrm{O}_{25}$, or the boat form ${ }^{24}$ of tetrametaphosphate, $\mathrm{Na}_{4} \mathrm{P}_{4} \mathrm{O}_{28}$.

\section{EXPERIMENTAL WORK}

\section{II.A. PRECIPITATION OF LINEAR PHOSPHATES}

Additional experiments were done on the separation of linear phosphates from the cyclic phosphates by precipitation of the former with barium chloride. The preparation of the samples and the procedure were the same as described on pp. 3 and 4 of the last report ${ }^{2 R}$ except where noted in Section III.A.

\section{II.B. ANION-EXCHANGE CHROMATOGRAPHY}

To prepare a polyphosphate mixture of $\bar{n} \cong 6$, sodium pyrophosphate decahydrate and sodium dihydrogen orthophosphate monohydrate were mixed in such amounts as to give an atomic ratio of sodium to phosphorus between 1.22 and 1.33. The mixture was heated gradually in a platinum boat and finally held at $540^{\circ} \mathrm{C}$. in an electric furnace for 12 hours. The melt was cooled rapidly between stainless-steel plates. The resulting glass was crushed 
and dissolved in $0.5 \mathrm{M}$ potassium chloride and stored in a refrigerator until used, never more than two months.

The eluents were solutions of potassium chloride buffered with acetate to the desired $\mathrm{pH}$ values. The total molarity of acetate was one-fortieth of that of the potassium chloride. Amberlite $\mathrm{XE}-119$ was used. This is an anion-exchange resin identical with Amberlite IRA-400 except that the size is 400 to 600 mesh. It contains trimethylbenzylammonium ions attached to a matrix of crosslinked polystyrene. The excessively fine particles were removed by repeated decantation of a suspension in water. Then it was washed exhaustively with $6 \mathrm{M}$ hydrochloric acid and then with $0.25 \mathrm{M}$ potassium chloride of $\mathrm{pH} 5.0$. The column had a cross-sectional area of $4.0 \mathrm{~cm} .8$ and a height of $28 \mathrm{~cm}$.

Five ml. of a solution containing the sample of phosphates in $0.25 \mathrm{M}$. potassium chloride of $\mathrm{pH}=5.0$ was added gently to the column, previously drained to the level of the resin. After this solution had drained to the level of the resin; $5 \mathrm{ml}$. of the $0.28 \mathrm{M}$ potassium chloride was added, care being taken to rinse the inside walls of the column. This rinsing was repeated with another portion of the same solution. The elution was then started with $0.28 \mathrm{M}$ potassium chloride at $\mathrm{pH} 5.0$. A flow rate of $154 \mathrm{ml}$. per $\mathrm{hr}$. or $0.64 \mathrm{~cm}$. per min. was maintained by the use of a Mini-pump (Milton Roy Company, Philadelphia), type NSI 12RH. Changes in the composition of the eluent were made at 
intervals during the elution as indicated in Figures 1 and 2. Fractions of $26.0 \mathrm{ml}$. were collected with an automatic fraction collector. The total phosphorus in the fractions was determined by a spectrophotometric method. ${ }^{20}$ A series of such elutions was performed with variations in the composition of the sample and the eluents in order to find the best conditions for the separation.

\section{II.C. ISOLATION OF THE UNKNOWN COMPOUND}

II.C.1. Removal of Acetate Buffer. Fractions 31 through 35 of Fig. 2 were mixed and diluted with $52 \mathrm{ml}$. of water to give a solution $0.25 \mathrm{M}$ with potassium chloride. This was adjusted to $\mathrm{pH}=7.0 \pm 0.3$ by the addition of $0.1 \mathrm{nt}$ sodium hydroxide. The solution was then passed through a column, $6.0 \mathrm{~cm} . \times 3.8 \mathrm{~cm} .{ }^{2}$, of Amberlite XE-119. Then 0.25M potassium chloride (unbuffered, $\mathrm{pH}=7.0 \pm 0.3)$ was passed through the column. The flow rate was maintained at $0.6 \mathrm{~cm}$. per min. The elution with $0.25 \mathrm{M}$ potassium chloride was continued until a negative test for acetate was obtained in the effluent.

The test for acetate consisted in adding $2.0 \mathrm{ml}$. of $0.0010 \mathrm{M}$ hydrochloric acid to a $26-\mathrm{ml}$. fraction and comparing the $\mathrm{pH}$ with that of a solution prepared from $26 \mathrm{ml}$. of eluent and $2.0 \mathrm{ml}$. of the hydrochloric acid. Identity of $\mathrm{pH}$ after the removal of carbon dioxide with nitrogen indicates the absence of acetate. After removal of the acetate, the elution was continued with $0.70 \mathrm{M}$ potassium chloride (unbuffered, $\mathrm{pH}=7.0 \pm 0.3$ ). 
of the unknown phosphate was contained in the first 26-ml. fraction of $0.70 \mathrm{M}$ potassium chloride.

The foregoing steps served to separate the unknown phosphate from the acetate but not from the potassium chloride, both of which accompanied the phosphate in the eluate. In some experiments, this solution (or an aliguot of it) was used for the titration of end groups, since potassium chloride does not interfere in this titration. In other experiments, the unknown phosphate was separated from the potassium chloride as follows.

II.C.2. Removal of Potassium Chloride. The solution was passed through a column, $6.0 \mathrm{~cm} . \times 3.8 \mathrm{~cm} .^{2}$, of Dowex $50-\mathrm{X} 4$, 200-400 mesh, hydrogen form. Then deionized water was passed through the column. The first $50 \mathrm{ml}$. of eluate contained all of the unknown phosphate as the free acid along with hydrochloric acid. In order to minimize the degradation of the polymer in this acid solution, these steps were performed in a refrigerator. The $50 \mathrm{ml}$. of effluent was immediately evaporated to about $1 \mathrm{ml}$. in a Rinco flash evaporator. The rapid evaporation maintained the temperature of the solution at about $5^{\circ} \mathrm{C}$. and avoided serious degradation. The small residue in the flask was treated with a small excess of 0.M sodium hydroxide.

The final solution contained the unknown phosphate as the sodium salt contaminated with small amounts of its degradation products, sodium chloride and sodium hydroxide. The quantities of these contaminants are probably not great enough to interfere 
seriously in the experiments described in Section II.E. This test was performed as soon as possible after the isolation of the unknown compound.

\section{II.D. TITRATION OF END GROUPS}

The titration of polyphosphoric acids with sodium hydroxide between the end points corresponding to the formation of $\mathrm{Na}_{n} \mathrm{H}_{2} \mathrm{P}_{n} \mathrm{O}_{3 \mathrm{n}+1}$ and $\mathrm{Na}_{n+2} \mathrm{P}_{n} \mathrm{O}_{3 n+1}$ is a well-known method ${ }^{16}$ for determining the value of $n$ of a pure compound or $\bar{n}$ of a mixture. The procedure described in this report is unusual only in regard to the very small sample of condensed phosphate taken for the titration.

A solution containing 14.8 micromoles of phosphorus as the unknown phosphate, freed of acetate as described in Section II.C, was treated with $0.1 \mathrm{M}$ hydrochloric acid until the $\mathrm{pH}$ was between 3.5 and 4.0. Nitrogen was bubbled through the solution to remove carbon dioxide. Then the solution was titrated with $0.118 \mathrm{M}$ sodium hydroxide in a Gilmont microburet. In order to test the reliability of the method with so small an amount of phosphate, a similar titration was done with about one micromole of essentially pure pentaphosphate. The method of Lingane was used to calculate the equivalence points.

\section{II.E. PAPER CHROMATOGRAPHY}

The unknown phosphate was isolated in about one $\mathrm{ml}$. of solution as described in Section II.C. Seven portions of three microliters each were applied to the same spot near a 
corner of Schleicher and Schuell orange-ribbon special chromatographic paper. A basic developer was applied in one direction, then an acidic developer in another. The developers and the procedure were the same as described by Van Wazer and Karl-Kroupa ${ }^{2}$ except that the development was done in a refrigerator to decrease the degradation.

\section{RESULTS AND CONCLUSIONS}

\section{III.A. PRECIPITATION OF IINEAR PHOSPHATES}

Table I contains the results of 18 experiments on the separation of linear from cyclic phosphates according to the procedure given in the last annual report. ${ }^{12}$ It should be noted that samples 11 to 15 were prepared somewhat differently from the others. Essentially pure trimetaphosphate (96\%) was dissolved in $0.38 \mathrm{M}$ potassium chloride with a $\mathrm{pH}$ of $5.0 \pm 0.1$. The small amounts of linear phosphates in this metaphosphate had been determined by the method of Peters. ${ }^{10}$ The mean error and standard deviation indicate that precipitation is a fairly good method for the determination of trimetaphosphate in the presence of linear polymers of $n=4$ and above. 
TABLE I

ANALYSIS OF SIMULATED ELUATE FRACTIONS CONTAINING LINEAR AND CYCLIC PHOSPHATES

\begin{tabular}{|c|c|c|c|c|c|c|}
\hline \multirow[t]{2}{*}{$\begin{array}{c}\text { Sample } \\
\text { no. }\end{array}$} & \multicolumn{2}{|c|}{$\begin{array}{c}\text { Taken, micro- } \\
\text { moles } \mathrm{P}\end{array}$} & \multicolumn{2}{|c|}{$\begin{array}{c}\text { Found, micro- } \\
\text { moles P }\end{array}$} & \multicolumn{2}{|c|}{$\begin{array}{c}\text { Error, micro- } \\
\text { moles } \mathrm{P} \\
\end{array}$} \\
\hline & Linear & Cyclic & Linear & Cyclic & Linear & Cyclic \\
\hline 1 & 65 & 0 & 61 & 4 & -4 & +4 \\
\hline 2 & 66 & 26 & 61 & 31 & -5 & +5 \\
\hline 3 & 68 & 71 & 67 & 72 & -1 & +1 \\
\hline $4^{b}$ & 70 & 117 & 54 & 133 & -16 & +16 \\
\hline 5 & 73 & 180 & 70 & 183 & -3 & +3 \\
\hline 6 & 72 & 0 & 72 & 0 & 0 & 0 \\
\hline 7 & 73 & 34 & 72 & 35 & -1 & +1 \\
\hline 8 & 75 & 68 & 74 & 69 & -1 & +1 \\
\hline 9 & 78 & 136 & 84 & 130 & +6 & -6 \\
\hline 10 & 81 & 203 & 85 & 200 & +4 & -3 \\
\hline 11 & 0 & 0 & 0 & 0 & 0 & 0 \\
\hline 12 & 0.5 & 13 & 0 & 14 & -1 & +1 \\
\hline 13 & 3.3 & 75 & 4.8 & 73 & +2 & -2 \\
\hline 14 & 4.9 & 112 & 6.0 & 111 & +1 & -1 \\
\hline 15 & 8.2 & 188 & 0 & 196 & -8 & +8 \\
\hline 16 & 29 & 0 & 28 & 0 & -1 & 0 \\
\hline 17 & 29 & 0 & 30 & 0 & +1 & 0 \\
\hline \multirow[t]{3}{*}{18} & 60 & 0 & 60 & 1 & 0 & +1 \\
\hline & & & \multicolumn{2}{|l|}{ Mean } & -0.7 & +0.8 \\
\hline & & & \multicolumn{2}{|c|}{ Standard deviatio } & \pm 3 & \pm 3 \\
\hline
\end{tabular}

${ }^{\text {aSamples } 1.5 \text { were included in the last annual report. }}$

bomitted in the calculation of the mean and the standard deviation. 


\section{III.B. ANTON-EXCHANGE CHROMATOGRAPHY}

Fig. I shows the elution graph of a mixture of equal weights of two polyphosphate glasses, one with $\bar{n} \cong 6$, the other with $\overline{\mathrm{n}} \cong 14$. Since these glasses contain very little ortho-, pyroor triphosphate, suitable quantities of these compounds were added to the sample. Since phosphate glasses contain small amounts of the two lowest cyclic compounds, the failure of the graph to reach an absorbance of zero between the peaks of tetra- and pentaphosphate is due to a poorly defined peak of tetrametaphosphate. Previous elutions of tetrametaphosphate under similar conditions indicate that its peak appears at this point. The peak marked "hexameta plus trimeta" consists mostly of the hexaphosphate, but similar elutions of trimetaphosphate indicate that it would be eluted at about fraction 77 along with the hexaphosphate.

Two features of Fig. I should be emphasized: (1) Although the two cyclic compounds are not separated from the linear, each linear phosphate is well separated from the others except for octa- and nonaphosphates. (2) \& small but definite peak at fraction 32 cannot be assigned to trimeta-nor tetrameta- nor any of the linear phosphates. It was the first indication of the presence of the "new compound" in fresh (i.e., only slightly degraded) polyphosphate glasses.

In order to isolate this new compound in fairly large quantity, an elution (Fig. 2) was performed with a larger sample of the glass of $\overline{\mathrm{n}} \cong 6$ to which some pure tetrametaphosphate was 
added. Samples 1 through 28, which surely contained only small guantities of ortho, pyro-and triphosphates were not analyzed. This elution was terminated at fraction 20 although there were surely some of the polymers above pentaphosphate present. The sequence of eluents was altered slightly from that of Fig. 1. This elution indicates (1) that a large quantity of unknown compound occurred, free from the other phosphates, in fractions 31 through 35 , (2) that tetraphosphate was separated from the other phosphates, and (3) that tetrametaphosphate appeared as a distinct peak overlapping somewhat with pentaphosphate.

From these two figures, it may be concluded that an elution under similar conditions can be used in conjunction with the precipitation of linear phosphates by barium chloride in those fractions where they are mixed with cyclic phosphates, to determine each constituent of a mixture consisting of the first nine linear phosphates, the two well-known cyclic phosphates and the new compound.

\section{III.C. ISOLATION OF THE UNKNOWN COMPOUND}

The unknown phosphate as it occurs in the eluate cannot be subjected to the end-group titration because the acetate buffer would obscure the end points; also the concentration of the phosphate in the eluate. is too small to permit a satisfactory titration. In the procedure described in Section II.C.I, the unknown compound contained in $130 \mathrm{ml}$. of eluent along with $455 \mathrm{mmol}$. of potassium chloride and 11 mmol. of acetate buffer is recovered 
in $26 \mathrm{ml}$. containing no acetate and only $180 \mathrm{mmol}$. of potassium chloride. This solution is suitable for the end-group titration. However, it is still not suitable for paper chromatography because the concentration is still too small and because the large amount of potassium chloride would interfere. By the procedure described in Section II.C.2, the unknown phosphate is recovered in about two $\mathrm{ml}$. almost entirely freed from potassium or sodium chloride.

\section{III.D. END-GROUP TITRATIONS}

Table II shows the results of the micro end-group titration of pentaphosphate. The average degree of polymerization is calculated by the equation

$$
\bar{n}=\frac{2 G}{\theta}
$$

where $G$ is the number of micromoles of phosphorus in the sample and $\theta$ is the number of micromoles of sodium hydroxide used between the end points. The result, $n=4.78$, is satisfactorily close to the theoretical value of 5 . The slightly low experimental result may be partly due to some degradation of the sample.

Since the micro end-group titration had been proved to be reliable by the titration of pentaphosphate, it was applied to the unknown phosphate. These data, given in Table III, are typical of a strong acid. No indication of two end points can be seen. Therefore, the unknown compound has no weakly ionizable hydrogens, i.e., no end groups; and it must be a cyclic phosphate. 


\section{TABLE II}

\section{END-GROUP TITRATION OF PENTAPHOSPHATE WITH $0.118 \mathrm{~N}$ SODIUM HYDROXIDE \\ Total phosphorus $=5.74$ micromoles}

\begin{tabular}{|c|c|c|c|}
\hline $\begin{array}{l}\text { Buret } \\
\text { reading, ml. }\end{array}$ & $\mathrm{pH}$ & $\Delta \mathrm{pH}$ & $\Delta^{2} \mathrm{pH}$ \\
\hline 0.0400 & 4.22 & & \\
\hline 0.0440 & 4.30 & & \\
\hline 0.0480 & 4.40 & 0.10 & \\
\hline 0.0520 & 4.55 & 0.17 & \\
\hline 0.0560 & 4.72 & 0.27 & \\
\hline 0.0600 & 4.99 & 0.33 & +0.06 \\
\hline 0.0640 & 5.32 & 0.45 & +0.12 \\
\hline 0.0680 & 5.77 & 0.36 & -0.09 \\
\hline 0.0720 & 6.13 & 0.38 & \\
\hline 0.0760 & 6.51 & 0.39 & \\
\hline 0.0800 & 6.90 & 0.44 & +0.05 \\
\hline 0.0840 & 7.34 & 0.63 & +0.19 \\
\hline 0.0880 & 7.97 & 0.53 & -0.10 \\
\hline 0.0920 & 8.50 & 0.33 & \\
\hline 0.0960 & 8.83 & 0.31 & \\
\hline 0.1000 & 9.14 & 0.20 & \\
\hline 0.1040 & 9.34 & & \\
\hline
\end{tabular}

First equivalence point $=0.0640+\frac{(0.0680-0.0640) 0.12}{0.12+0.09}=0.0663$ Second equivalence point $=0.0810+\frac{(0.0880-0.0840) 0.19}{0.19+0.10}=0.0866$ $(0.0866-0.0663) \times 0.118=0.00240 \mathrm{mmol}$. or $2.40 \mathrm{micromole}$ of $\bar{n}=\frac{5.74 \times 2}{2.40}=4.78 \cong 5$

end group 


\section{TABLE III}

END-GROUP TITRATION OF UNKLYOWN COMPOUND

Total phosphorus $=14.8 \mathrm{micromoles}$

$\begin{array}{ccc}\begin{array}{c}\text { Buret } \\ \text { reading, ml. }\end{array} & \mathrm{pH} & \Delta \mathrm{pH} \\ 0.0300 & 4.09 & 0.10 \\ 0.0340 & 4.19 & 0.16 \\ 0.0380 & 4.35 & 0.22 \\ 0.0420 & 4.57 & 0.42 \\ 0.0460 & 4.99 & 2.10 \\ 0.0500 & 7.09 & 1.44 \\ 0.0540 & 8.53 & 0.38 \\ 0.0580 & 8.91 & 0.27 \\ 0.0620 & 9.18 & 0.14 \\ 0.0660 & 9.32 & \end{array}$

The success of the micro end-group titration is important from two other points of view:

(1) Until recently, it had been assumed that the linear phosphates emerged from the column in the order of increasing values of $n$. Wieker ${ }^{18}$ has shown by means of paper chromatography of the hydrolysis products that this is true for pentaphosphate through octaphosphate. Now the micro end-group titration offers

a method of confirming Wieker's work and of extending the proof of identity to polymers beyond the range of applicability of paper chromatography. 
(2) In the end-group titration of a mixture of a linear and a cyclic phosphate, ecuation (1) would be changed to

$$
n=\frac{2(G-R)}{\theta}
$$

where $R$ is the total number of micromoles of phosphorus in the cyclic compound and the other symbols have their previous significance. This equation could be used to determine the quantity of cyclic phosphate in a fraction containing both a linear and cyclic phosphate. The value of $n$ would be known from the position in the elution graph; $\theta$ is determined by end-group titration and $G$ by spectrophotometry of the totally degraded fraction; thus $R$ can be calculated. This method may prove to be more useful than the precipitation of the barium salts of the linear compounds.

\section{III.E. PAPER CHROMATOGRAPHY}

Paper chromatography of the unknown compound resulted in a spot which moved only in basic solution and was found in the cyclic range. Standard spots were applied high on the paper so that they moved in only one solvent each. Tetrametaphosphate moved in base and after basic elution tetraphosphate was put on to move in acidic solution. A summary of a paper chromatogram is shown in Table IV. 


\section{TABLE IV}

$\begin{array}{lcc} & \text { in acid } & \text { Rf } \\ & 0.00 & \text { in base } \\ \text { Unknown cyclic } & 0.32 & 0.35 \\ \text { Tetraphosphate } & \ldots .- & 0.39 \\ \text { Tetrametaphosphate } & & \\ \text { Acid front travelled } & 22.6 \mathrm{~cm} . \\ \text { Base front travelled } & 16.7 \mathrm{~cm} .\end{array}$

This is another proof of the cyclic structure of the compound designated as unknown cyclic. Unfortunately, it is not possible to state which particular cyclic ion it is; but it is not identical with the samples of tri- or tetrametaphosphate which have been prepared in this laboratory. This difference is evidenced by its behavior in an ion-exchange separation.

IV. FUTURE PLANS

IV.A. ANALYSIS OF LINEAR AND CYCLIC PHOSPHATES IN THE PRESENCE OF ONE ANOTHER

It has been shown that barium precipitation is a useful technique for the determination of linear and cyclic polymers in the presence of one another. The end-group titration will be tested as a method for this and compared with the precipitation method. 
IV.B. IMPROVEMENT OF THE CHROMATOGRAPHIC TECHNIQUE Attempts will be made to improve the separation of the condensed phosphates br anion-exchange chromatography.

IV.C. IDENTIFICATION OF THE UNKNOWN CYCLIC

There are at least two methods that should be applicable in the structure determination of this compound: (1) Basic hydrolysis opens the ring ${ }^{21,13}$ to give the corresponding chain. The subsequent determination of the hydrolysis products by ion-exchange chromatography should indicate the size of the ring. (2) Cryoscopic determinations in sodium sulfate decahydrate ${ }^{2}$ and water ${ }^{\circ}$ have shown tetrametaphosphate to be a four-membered ring with a quadruply charged anion, respectively. Either or both of these methods will be used to determine the structure of the unknown cyclic phosphate.

\section{IV.D. IDENTIFICATION OF ALI PEAKS}

The peaks corresponding to ortho- through tetraphosphate as well as those belonging to trimeta- and tetrametaphosphate have already been characterized. ${ }^{20}$ The identification of all the remaining peaks by the use of micro end-group titration techniques will be attempted.

IV.E. SEARCH FOR HIGHER CYCLICS

The existence of cyclic compounds larger than the tetramer has been demonstrated. It has been found that the two well-known cyclics are eluted in the inverse order of their size. ${ }^{20}$ If it is found, as seems likely, that the unknown compound is 
pentametaphosphate, the inverse relationship between the order of elution and the molecular weight of the cyclic polymers will have been validated for three members of this series.

It would be interesting to search for higher cyclic polymers in the earlier fractions of eluate (around triphosphate) in the elution of phosphate glasses.

\section{ACKNOWLEDGMENT}

The authors express their gratitude to the Atomic Energy Commission for the financial support of this work. 


\section{REFERENCES}

1. Bonneman, P., Compt. rend. 204, 865 (1937).

2. Grande, J. A., and Beukenkamp, J., Anal. Chem., 28, 1497 (1956).

3. Jameson, R. F., J. Chem. Soc., 752 (1959).

4. Kolloff, R. H., ASTM Bull. No. 237, 74 (1959).

5. Lingane, J. J., "Electroanalytical Chemistry," 2nd ed., Interscience, New York, 1958, p. 93.

6. Lundgren, D. P., Ann. N. Y. Acad. Sci., 87, 904 (1960).

7. Lundgren, D. P., and Loeb, N. P., Anal. Chem., 33, 366 (1961).

8. Matsuhashi, N., J. Biochem. (Tokyo), 44, 65 (1957).

9. Nylen, P., Z. anorg. u. allgem. Chem., 229, 30 (1937).

10. Peters, T. V., and Rieman, W., Anal. Chim. Acta, 14, 131 (1956).

11. Quimby, 0. T., J. Phys. Chem., 58, 603 (1954).

12. Rieman, W., Report on Contract AT(30-1)-1306 (Oct. 18, 1960).

13. Thilo, E., and Rätz, R., Z. Anorg. Chem., 260, 255 (1949).

14. Van Wazer, J. R., "Phosphorus and Its Compounds," Interscience, New York, 1958, vol. I, p. 699.

15. Ibid., p. 444.

16. Ibid., p. 702 .

17. Van Wazer, J. R., and Karl-Kroupa, E., J. Am, Chem. Soc., 78, 1772 (1956).

18. Wieker, W., Z. Elektrochem., 64, 1047 (1960), 


\section{REPORTS AND PAPERS RESULTING FROM WORK OF THIS CONTRACT}

1. Report, NYO-3440, Aug. 24, 1953.

2. Report, NYO-3441, covering the period from Feb. 1, 1953 to Oct. 31, 1953.

3. Report, NYO-3442, June 8, 1954.

4. Report, NYO-3443 (Revised), Jan. 7, 1955.

5. Report, NYO-3444, June 8, 1955.

6. Report, NYO-3445, covering the period from Nov. 1, 1954 to Oct. 31, 1955.

7. Report, NYO-3446, covering the period from Nov. 1, 1955 to Sept. 30, 1956.

8. Report, NYO-3447, covering the period from Oct. I, 1956 to Aug. 30, 1957.

9. Report, NYO-3448, covering the period from Sept. 1, 1957 to July 15, 1958.

10. Report, NYO-2916, covering the period from July 16, 1958 to Sept. 30, 1959.

11. Report, Oct. 18, 1960.

12. Behavior of the Condensed Phosphates in Anion-Exchange Chromatography, Anal. Chem., 26, 505 (1954).

13. Analysis of Mixtures of the Condensed Phosphates by Ion-Exchange Chromatography, Anal. Chim. Acta, 11, 530 (1954).

14. Analysis of Mixtures of the Condensed Phosphates by Ion-Exchange Chromatography. II. Mixtures of Ortho-, Pyro-, Tri-, Tetra-, Trimeta- and Tetrametaphosphates and Graham's Salt, Anal. Chim. Acta, 14, 131 (1956).

15. Molecular-weight Distribution of Graham Salt, J. Polymer Sci., in press. 
Figure 1 - Elution of a mixture of condensed phosphates by potassium chloride at $\mathrm{pH}$ 5.0.

Absorbance at $400 \mathrm{~m} \mu$ plotted versus fraction number. Each fraction equals $26 \mathrm{ml}$.

Molarities of $\mathrm{KCl}$ are indicated on the graph.

\begin{tabular}{|c|c|c|c|c|}
\hline Symbol & Name & \multicolumn{3}{|c|}{ in milligrams } \\
\hline Or & orthophosphate & 12. & & \\
\hline Py & pyrophosphate & 15. & & \\
\hline $\operatorname{Tr}$ & triphosphate & & .0 & \\
\hline Trm & trimetaphosphate & contained & in $\varepsilon$ & glasses \\
\hline Tem & tetrame taphosphate & $"$ & $"$ & $"$ \\
\hline $\mathrm{Te}$ & tetraphosphate & $"$ & $"$ & $"$ \\
\hline $\mathrm{Pe}$ & pentaphosphate & $"$ & $"$ & $"$ \\
\hline $\mathrm{Hx}$ & hexaphosphate & $"$ & $"$ & $"$ \\
\hline Hp & heptaphosphate & $"$ & $"$ & $"$ \\
\hline Oc & octaphosphate & $"$ & $"$ & $"$ \\
\hline $\mathrm{Nn}$ & nonaphosphate & $"$ & $"$ & $"$ \\
\hline Dc & decaphosphate & $"$ & $"$ & $"$ \\
\hline Glass, $\bar{n} \cong 6$ & & 45 & & \\
\hline Glass, $\bar{n} \cong 14$ & & 45 & & \\
\hline
\end{tabular}



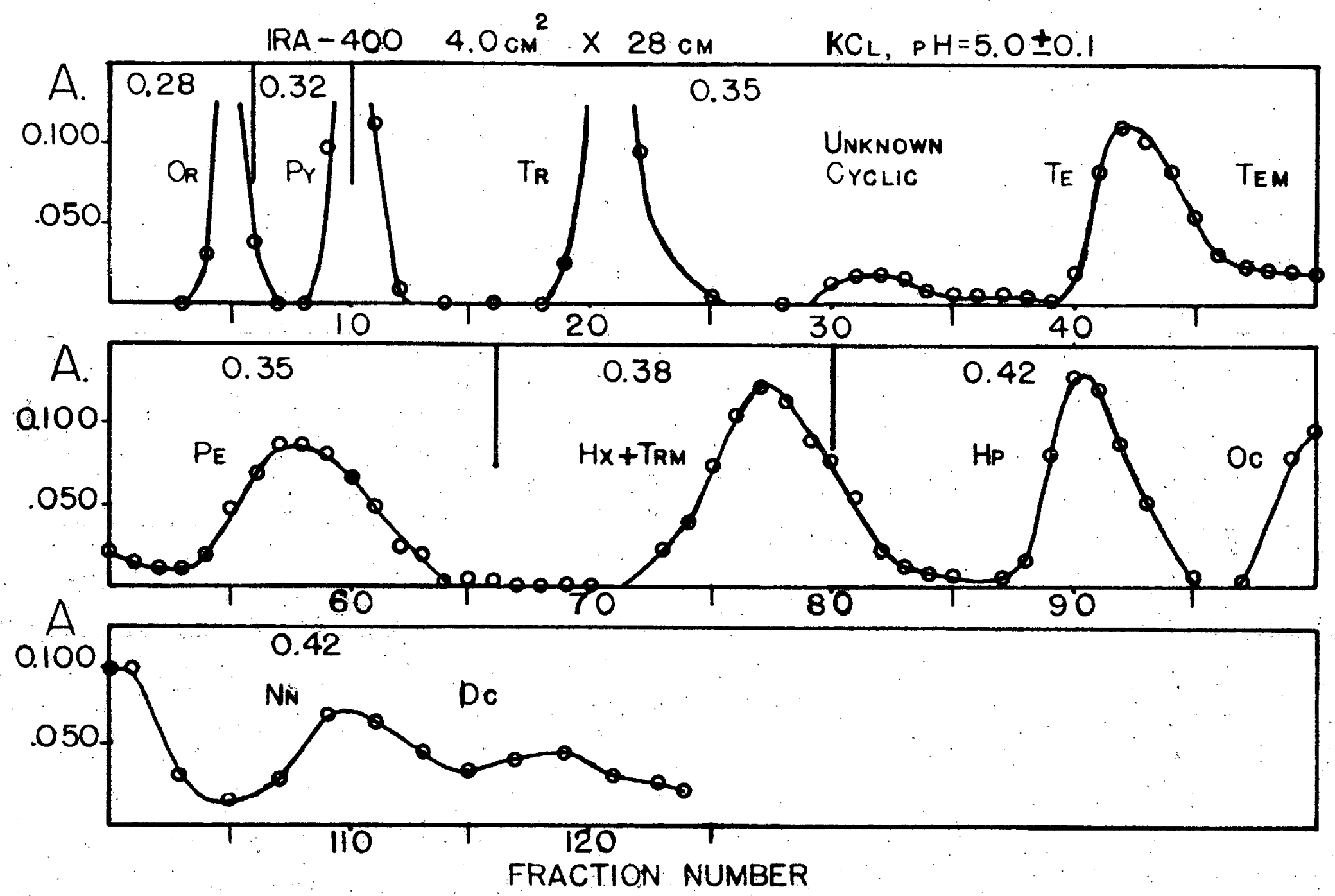


$$
\cdots, \cdots
$$

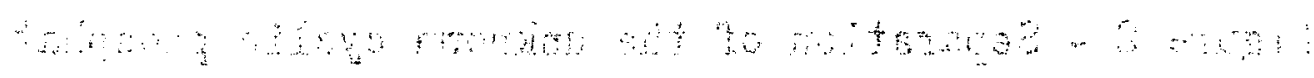

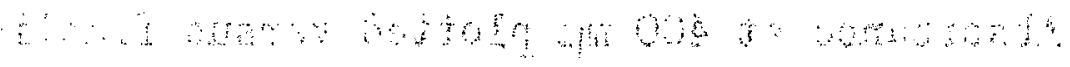

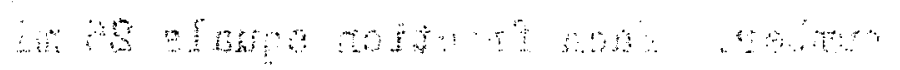

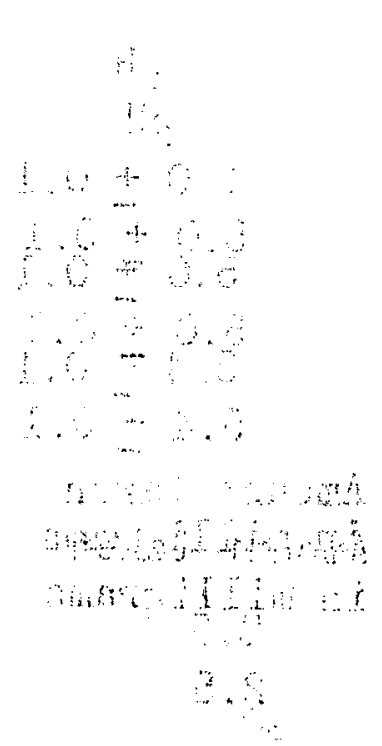

20: $: 2:$ :

intis

$\because$

$\therefore$

$\because \because !$

$\therefore, \therefore$

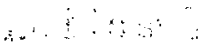

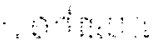

$\cdots \cdots$

ij:

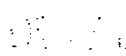

$\therefore$

$\therefore$ 


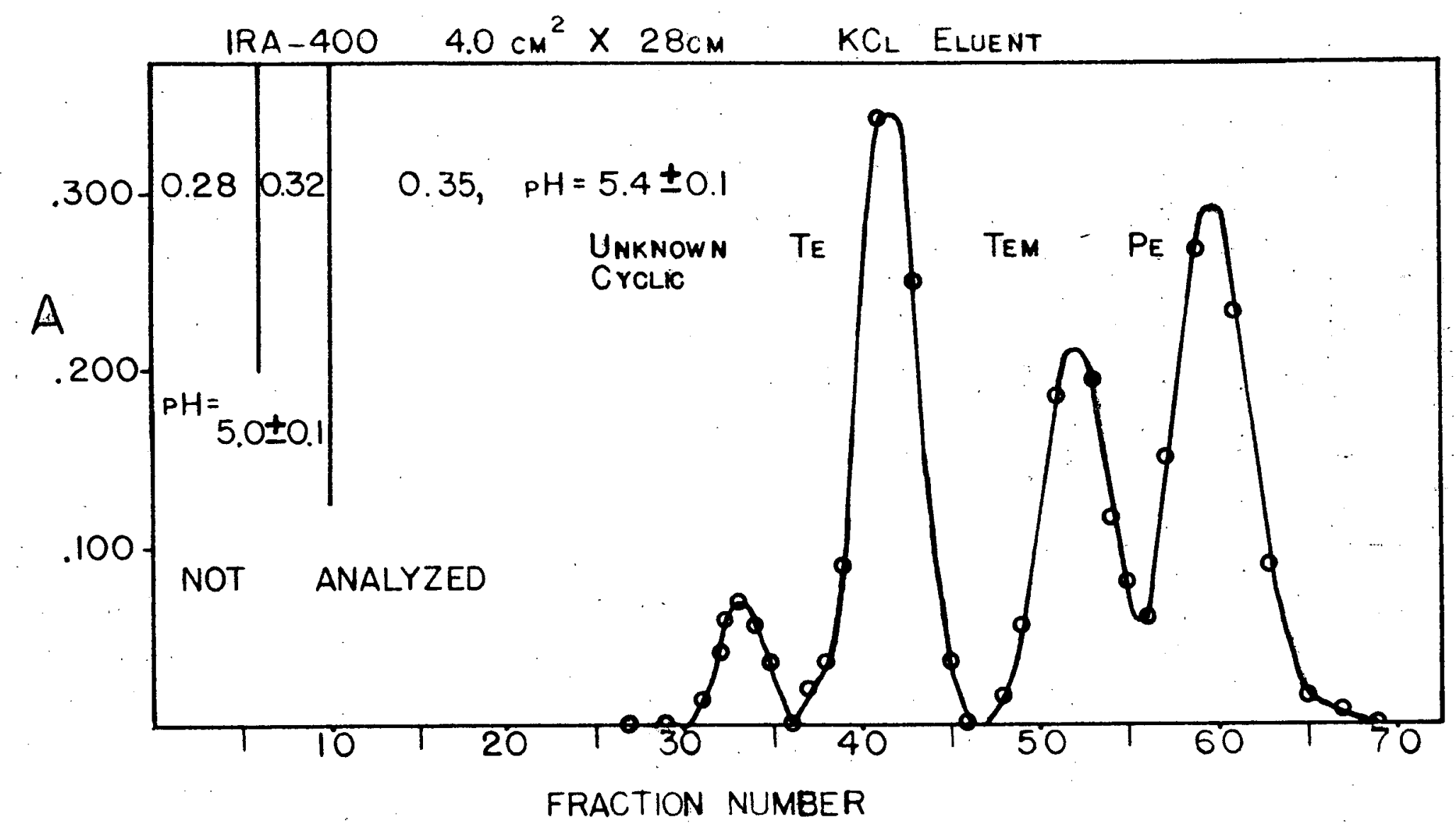

$\omega$ 